\title{
Analgesic effect of the interferential current in chronic low back pain management
}

\author{
Efeito analgésico da corrente interferencial no manuseio da dor lombar crônica
}

DOI 10.5935/2595-0118.20190036

Dear Editor,

We've read with great interest the paper "Immediate analgesic effect of the $\mathbf{2} \mathbf{K H z}$ interferential current in chronic low back pain: randomized clinical trial" . Neuromodulation is based on the concept that the electrical stimulation-induced paresthesia can be analgesic. Its historical basis emanates from the gate control theory of pain proposed by Melzack and Wall in $1965^{2}$. Neuromodulation gave us access to pain modulation systems and helped to mature the understanding of the pathophysiology of pain ${ }^{3}$. However, the current understanding of pain is still rudimental and the evidence that neuromodulation works, is modest. A current review conducted by Cochrane concluded that "we are still unable to conclude with confidence that in people with chronic pain, the transcutaneous electrotherapy is detrimental or beneficial to control pain, disability, health-related quality of life, drug use for pain relief or overall perception of change" ${ }^{4}$. However, the results presented by this study have convinced us that the interferential current has its role in the management of chronic low back pain; not because of its long-term analgesic effect but because of its immediate analgesic effect that proved to be satisfactory in the preparation of the patient to receive kinesiotherapy, which has more robust levels of evidence in the control of chronic low back pain ${ }^{5}$. That is, electrotherapy is not a panacea, much less the basis of the non-surgical management of low back pain, but it can play its role as a bridge to access more robust therapies, relieving immediate pain, thus allowing the beginning of other therapies. We encourage the authors to continue the work investigating the behavior of pain in other frequencies and perhaps to elaborate a protocol for the adjuvant use of the interferential current in the treatment of chronic low back pain.

Keywords: Analgesia, Low back pain, Electrical stimulation therapy.

Conflict of interests: none - Sources of support: none.

Ricardo Vieira Teles Filho

Universidade Federal de Goiás, Faculdade de Medicina, Departamento de Ortopedia e Traumatologia, Goiânia, GO, Brasil. (D) https://orcid.org/0000-0003-4822-1526.

E-mail:ricardovteles@gmail.com

\section{REFERENCES}

1. Almeida N, Paladini LH, Pivovarski M, Gaideski F, Korelo RI, Macedo AC. Immediate analgesic effect of $2 \mathrm{KHz}$ interferential current in chronic low back pain: randomized clinical trial. BrJP. 2019;2(1):27-33.

2. Melzack R, Wall PD. Pain Mechanisms: a new theory. Science, 1965;150(3699):971-9.

3. Kumar K, Rizvi S. Historical and present state of neuromodulation in chronic pain. Curr Pain Headache Rep. 2014;18(1):387.

4. Gibson W, Wand BM, Meads C, Catley MJ, O'Connell NE. Transcutaneous electrical nerve stimulation (TENS) for chronic pain - an overview of Cochrane Reviews. Cochrane Database Syst Rev. 2019;(2):CD011890.

5. Adamczyk WM, Buglewicz E, Szikszay TM, Luedtke K, Bąbel P. Reward for pain: hyperalgesia and allodynia induced by operant conditioning: systematic review and meta-analysis. J Pain. 2019;25. (Epub ahead of print]. 